\title{
Study of the Mechanical Behavior of LM20 Alloy at Various Temperatures Processed By Die-Casting
}

\author{
Muralidhar Avvari, Mashamba Able
}

\begin{abstract}
Now a day's in the current domain, manufacturing industries are competing to reduce the cost and fuel consumption rates. Especially, in automobile and aerospace applications because of the improvement of lightweight metal advantages. Magnesium, aluminum and other few materials are considered as lightweight materials to use in required applications due to their inherent properties. Therefore, in this paper tried to characterize the advances of LM20 aluminum alloy rods by using the die-casting processes at various processing temperatures followed by room temperature, $373 \mathrm{~K}$, and $473 \mathrm{~K}$. The main aim is to study the effect of various processing temperature on microstructures and mechanical properties of LM20 alloy. Also, this paper reveals the stability of the microstructures of LM20 aluminum alloy though the processing temperature has been increased. The tensile strength, hardness of the LM20 aluminum alloy was decreased with increase in processing temperature. Similarly, the wear, and surface roughness tests were performed on the LM20 alloy rods to understand the effect at various processing temperature.
\end{abstract}

Keywords- LM20, Die-casting, Microstructures, Mechanical Properties, and Surface roughness.

\section{Introduction}

LM20 aluminum alloy has been widely used in many applications like marine casting products, meter cases, water jackets, interior design equipment, street lightening and other castings products subjected to atmospheric exposure [1]. The reason behind these numerous applications are having many advantages of LM20 along with their inherent properties. They are excellent fluidity, wettability, formability, high specific strength, good castability, shrinkage reduction, corrosion resistance, low thermal expansion coefficient, wear resistance [2]. Also, Light Metals (LM) would became strong alloys as the combination of alloying elements (Al-Si-Cu-Mg-Ni), hence, using many industrial applications [3]. However, mechanical properties are reflected by stringent limitations to achieve these applications while processing using conventional methods [4].

Dr. Muralidhar Avvari

Department of Mechanical and Engineering Technology

University of Johannesburg

Johannesburg, South Africa

Dr. Mashamba Able

Department of Mechanical and Engineering Technology

University of Johannesburg

Johannesburg, South Africa
Therefore, these alloying properties especially porosity and stringent limitations need to be minimized by changing the conventional methods and processing temperatures. Also, Aluminum and silicon content alloys mechanical properties have been influenced by their particle size, shape and distribution $[5,6]$. However, there are several casting approaches to modify the size, shape and distribution of the alloys but, attaining expected outcomes would be possible through heat treatment processes while conducting the experiments [7]. Consequently, Fan et al., illustrated the influence of casting temperatures on microstructure, and its mechanical properties of $\mathrm{Al}-\mathrm{Zn}-\mathrm{Mg}-\mathrm{Cu}$ alloy [8]. Maleki et al., considered the most influencing process parameters such as squeeze pressure, melt and die temperature to explore the effects on grain size of the LM13 alloy, and aspect ratio of eutectic silicon particles [9]. Wang et al., made an attempt to predict the temperature difference of the squeeze cast part at different casting conditions utilizing with back propagation algorithm of ANNs [10].

From the above review of literature, it is defined that casting process parameters also decides the final cast structure and on its mechanical properties. The aim of the present work is to explore the effects under experimental studies at various processing temperatures. An attempt made to experimentally investigate the final solidified structure using mechanical modification process parameters such as pouring and die temperatures.

\section{Experimental Work}

In the present work LM20 aluminum alloy was used as a casting material due to its stimulating features and the alloy chemical composition was performed using the spectroscopy test to confirm the exact composition as equivalent to the ASTM E1251-07 standard. Table 1, shows the chemical composition of the LM20 alloy. Besides, H13 hot die steel was used as die material to endure at various temperatures while performing the casting processes. Fig.1 shows the cylindrical cavity which was used to obtain the cylindrical samples of LM20 alloy. Experiments have been carried out on LM20 alloys at various die temperatures of room temperature, $373 \mathrm{~K}$, and $473 \mathrm{~K}$ with constant muffle furnace temperature. Initially, as-received LM20 ingots were heated up to $1073 \mathrm{~K}$ by using the controlled muffle furnace and the stirrer was fixed to mix properly to dissolve all elements in equal distribution. Suitable cover flux and hexachloroethane was used to clean the surface and to eliminate excessive gasses respectively while melting. Once melting was done, started pouring into the hot die which was maintained to the 
room temperature to get five decent cylindrical shaped samples as shown in fig. 2 .

TABLE 1. ChEMiCAL COMPOSITION OF LM20 Alloy

\begin{tabular}{|l|l|l|l|l|l|l|l|l|l|l|}
\hline Elements & $\mathbf{S i}$ & $\mathbf{F e}$ & $\mathbf{C u}$ & $\mathbf{M n}$ & $\mathbf{M g}$ & $\mathbf{C r}$ & $\mathbf{N i}$ & $\mathbf{Z n}$ & $\mathbf{T i}$ & $\mathbf{A l}$ \\
\hline $\begin{array}{l}\text { Composition of } \\
\text { LM20 (\%) }\end{array}$ & 10.4 & 0.29 & 0.18 & 0.53 & 0.18 & 0.017 & 0.016 & 0.35 & 0.18 & 87.84 \\
& & & & & & & & & & \\
\hline
\end{tabular}

Similarly, experiments were conducted at various temperatures of $373 \mathrm{~K}$, and $473 \mathrm{~K}$. The obtained sample was divided by performing the machining operations and distributed for the various tests to study the behavior of the LM20 alloy at various temperatures. After completion of experimental work, the specimens are to be used for multipurpose testing such as microstructural characterization and mechanical testing. The specimen must have the fine structure by polishing for characterization and for check hardness. Furthermore, part of the specimen is to be used to prepare the standard tensile specimens for observe the strength and elongation of the material. Also, in the present work, surface roughness analysis has been carried out.
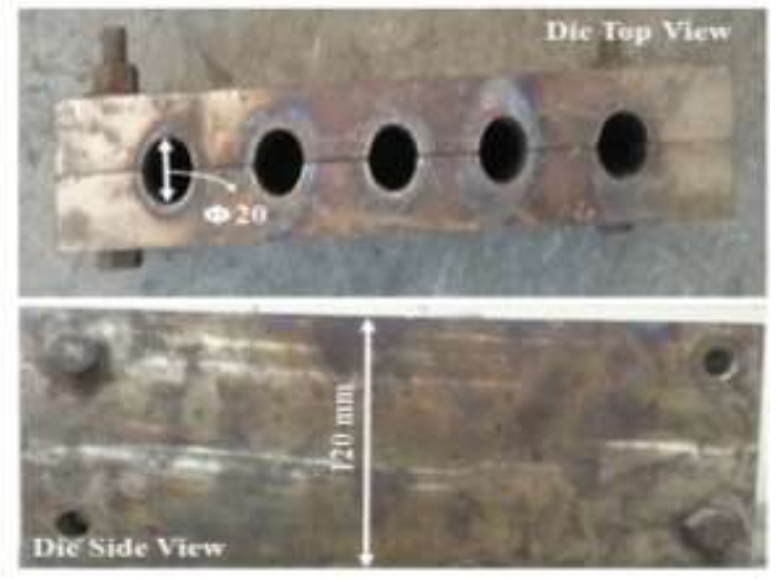

Figure 1. Die Cavity

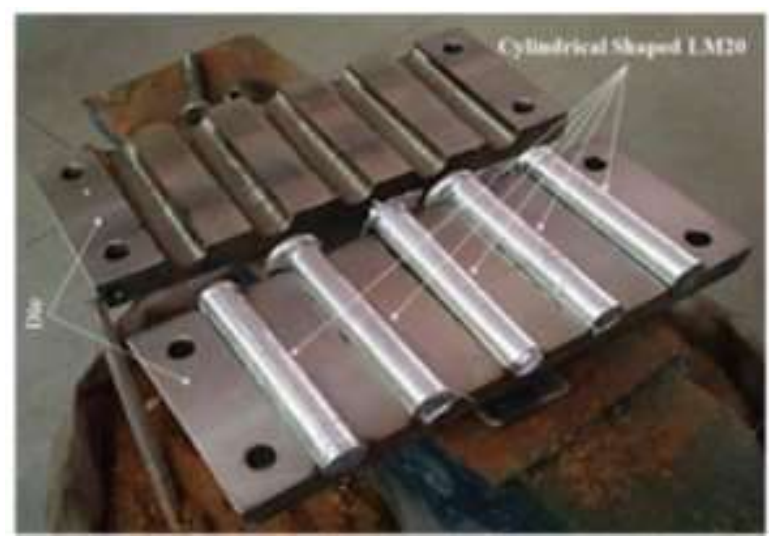

Figure 2. LM20 cylindrical shaped specimens

The microstructure evaluation was done on LM20 aluminum alloys using an Optical Microscope (OM). These samples are to be prepared by mechanical polishing with silicon carbide abrasive papers (grades of 400, 600, 800,
$1000,1200,1500,2000,2 / 0,4 / 0)$ followed by electropolishing (etched) using a solution composed of Kellers reagent [11]. Mechanical properties (YS, UTS, \%Elongation, Hardness, Compression, and Wear) were studied for obtained LM20 alloy rods at various temperatures. Moreover, surface roughness analysis has been carried out to know the smoothness of the surface of the LM20 alloys.

\section{Results and Discussion}

Die-casting has been used to study the behaviour of the LM20 alloy by varying the die temperatures of room temperature, $373 \mathrm{~K}$, and $473 \mathrm{~K}$. In the present work, the following studies were conducted to know the behaviour of LM20 alloy.

- Microstructure analysis

- Hardness test

- Tensile test

- Wear test

- Surface roughness test

\section{A. Microstructure Analysis}
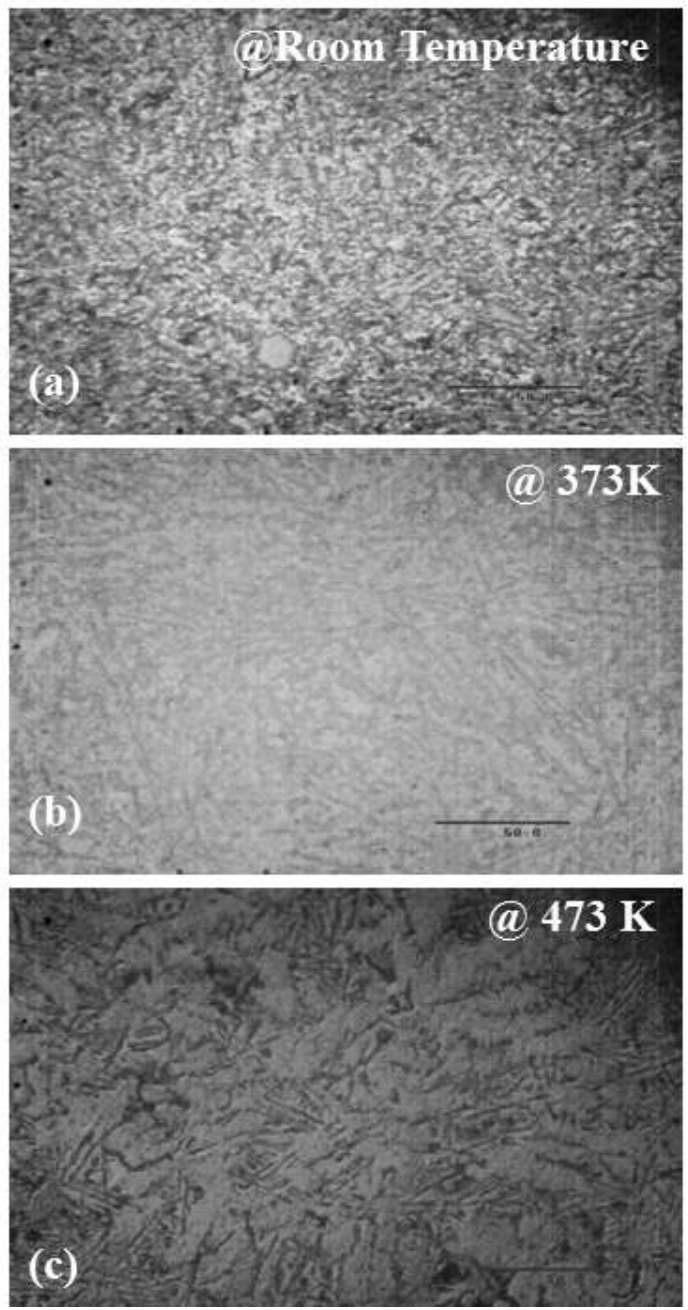

Figure 3. Optical microscope images of LM20 alloy at (a) Room Temperature, (b) $373 \mathrm{~K}$, and (c) $473 \mathrm{~K}$. 
The microstructural studies has been done on LM20 alloy to reveal the arrangement of the internal structures. The microstructures helps to understands the stability of the grain structure and how the properties are changing by varying grain sizes at different processing die temperature [12]. Fig. 3 shows the optical microscopy images of LM20 alloy processed at (a) Room Temperature, (b) $373 \mathrm{~K}$, (c) 473 $\mathrm{K}$ by using the $40 \mathrm{X}$ magnification. In fig 3(a), the grains were distributed with $\mathrm{Si}$ particles in the LM20 alloy processed at room temperature. However, dendrites were not found which must be available in the cast aluminum alloys. But, on contrary, the dendrites were found in the LM20 alloy after processing through squeeze casting [13]. Fig. 3(b)-(c) represents the coarse grains when compared to the grains where distributed in fig. 3(a). Similarly, the dendrites were not found in fig. 3(b)-(c). Manjunath et al., processed the LM20 alloy by using the squeeze casting at various temperatures and pressures to enhance the mechanical properties. Moreover, author added grain refineries to enhance the mechanical properties by changing the microstructures in LM20 alloy [14]. But, in the present work, we have found the grain boundaries without adding the grain refineries. It would be the eutectic $\mathrm{Si}$, and other elements involved to play a major role to form the microstructures. Vandana et al., conducted experiments on Al-Si alloy with different sources of Ni. Author, concluded that eutectic Si phase, size and distribution could influence in the microstructure and mechanical properties [15]. Similarly, in this paper, microstructural changes would occurred due to $\mathrm{Si}$ and other elements distribution in LM20 alloy.

\section{B. Hardness}

Fig. 4 describes the hardness of the LM20 alloy at various processing temperatures of $300 \mathrm{~K}, 373 \mathrm{~K}$, and 473 $\mathrm{K}$. At room temperature $(300 \mathrm{~K})$, the hardness of the LM20 alloy was found to be $84 \mathrm{Hv}$. The hardness of alloy was observed to be decreased with increase in processing temperature to $373 \mathrm{~K}$ from room temperature. It was drastically decreases to $79 \mathrm{Hv}$ at a processing temperature of $473 \mathrm{~K}$, when compared to the hardness at room temperature.

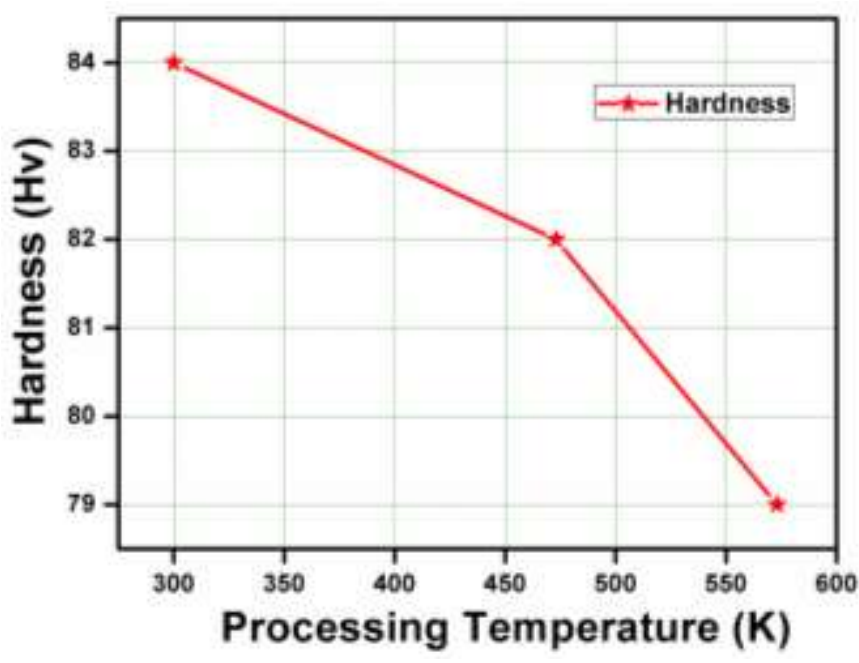

Figure 4. Hardness Vs Processing Temperature of LM20 Alloy after die-casting.
The hardness of the LM20 alloy was decreases with increase in processing die temperature is because of the recrystallization taken place. Therefore, the softness was increases at elevated temperatures. Similarly, the hardness of the alloy was decreased with increasing in processing temperatures [16].

\section{Tensile Test}

Fig. 5 represents the Ultimate Tensile Strength (UTS) and percentage of Elongation graphs against the processing die temperatures. The tensile strength of the alloy was decreased with increase in processing temperature but the percentage of elongation was increased vice versa. Muralidhar et al., developed AZ31 alloy at various processing die temperatures and author concluded that the strength of the material was decreased with increase in temperature [17]. Azushima et al., reviewed and concluded that the strength of the material was inversely proportional to the grain size [18]. Also, the hall-petch equation describes clearly that the strength of the material depends upon the grain diameter [19]. Similarly, in the present study, optical micrographs represents the variation of the grains (fine grains to coarse grains) in the LM20 alloy at elevated temperatures as shown in fig. 3. Hence, the tensile strength of the LM20 alloy was decreased. Besides, the percentage elongation was increased with decrease in strength at elevated temperatures.

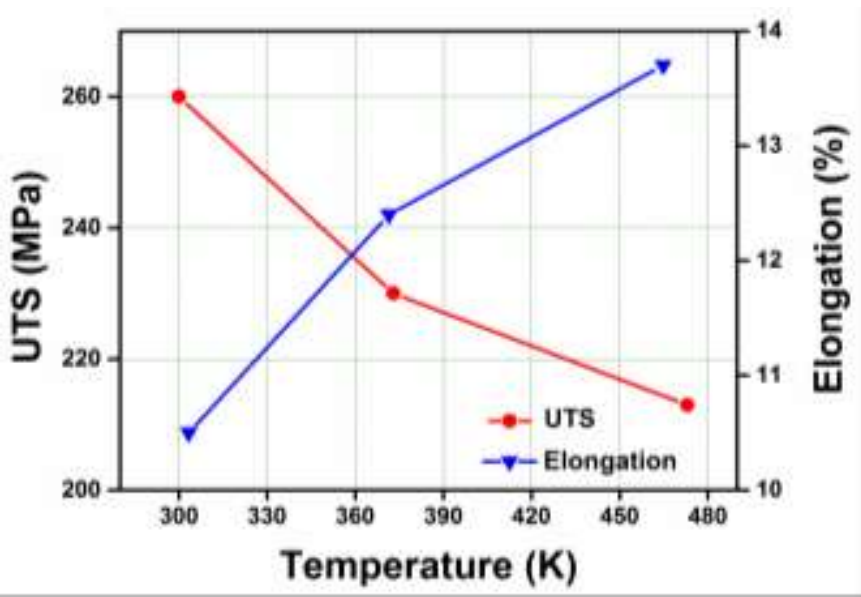

Figure 5. Ultimate tensile strength and percentage Elongation against three processing temperature for LM20 alloy after die-casting.

\section{Wear Test}

Fig. 6 and Fig. 7 shows the curves for wear rate against the time in seconds at various three processing die temperatures. In fig. 6, the wear tests were conducted by applying the $1 \mathrm{~kg}$ load and the load was increased to $2 \mathrm{~kg}$ and performed the wear test for various time durations in fig. 7. In this paper, the speed $250 \mathrm{rpm}$ kept constant for both the loads and conducted experiments to know the behavior of the LM20 alloy at various processing temperatures by changing the time durations from 120 seconds to 600 seconds. The hardness of the LM20 alloy was slightly increased with increase in time duration. But, the wear rate was increased greatly with increase in processing die temperature even for both $1 \mathrm{~kg}$ and $2 \mathrm{~kg}$ loads. Also, the wear rate was higher at $2 \mathrm{~kg}$ load when compared to wear rate at $1 \mathrm{~kg}$ load. Archard model, says that the wear volume was not followed the linear trend with the 
applied load [20]. Similarly, the trend of the wear curves was not linear with load.

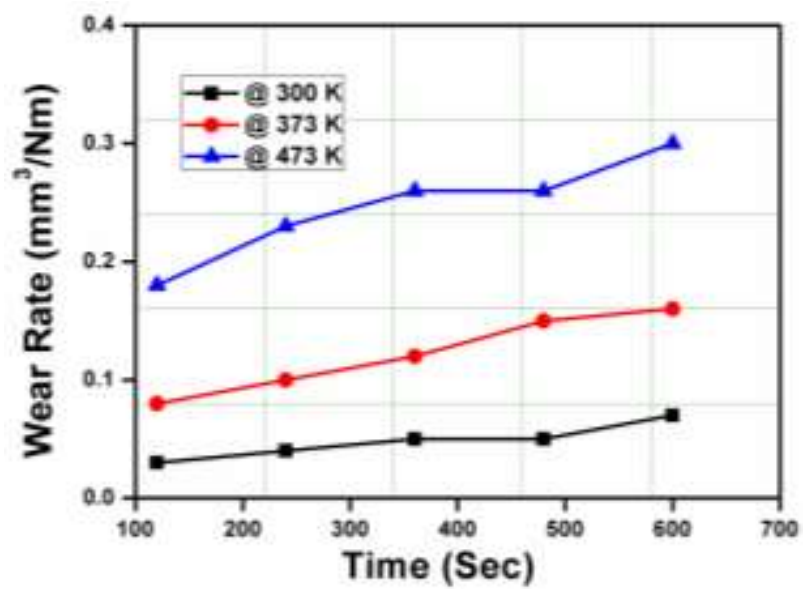

Figure 6. Wear rate against time in seconds for LM20 alloy at $1 \mathrm{~kg}$. load with three processing temperatures.

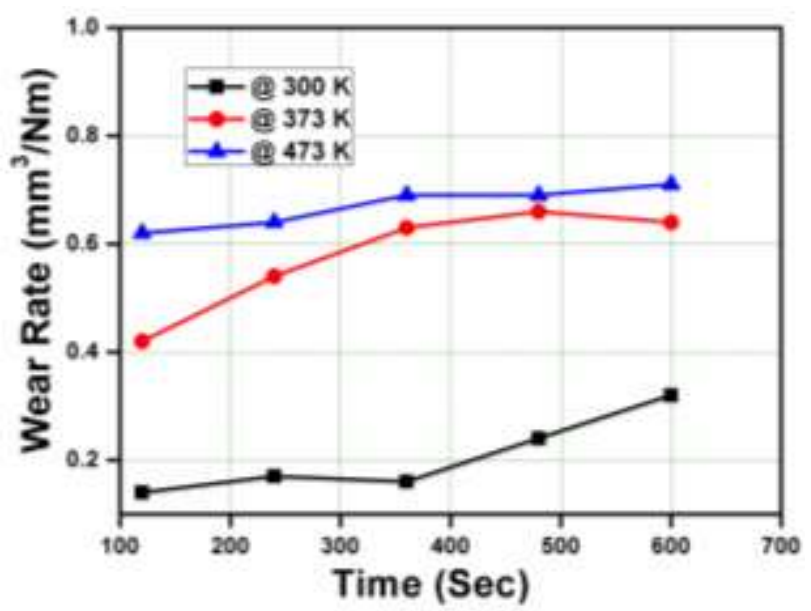

Figure 7. Wear rate against time in seconds for LM20 alloy at $2 \mathrm{~kg}$ load with three processing temperatures.

\section{E. Surface Roughness Test}

The surface roughness was conducted on LM20 alloys at various processing die temperatures which was tabulated in table 2. The smooth surface was found where, the specimen casted at room temperature for the Ra value is 0.29 . But, the roughness was increased at elevated temperatures like $\mathrm{Ra}$ value is observed to be 0.30 and 0.48 microns respectively.

TABLE 2. SURFACE FINISH DATA FOR THREE SELECTED PROCESSING TEMPERATURES OF LM20 ALLOY AFTER DIE-CASTING

\begin{tabular}{|c|c|c|c|}
\hline & $\mathbf{R a}$ & $\mathbf{R y}$ & $\mathbf{R z}$ \\
\hline LM20@RT & 0.29 & 2.92 & 2.92 \\
\hline LM20@373 K & 0.30 & 3.58 & 3.58 \\
\hline LM20@473 K & 0.48 & 6.39 & 6.39 \\
\hline
\end{tabular}

\section{Summary}

In the present work, the evaluation of microstructures and mechanical properties were studied on LM20 alloy at various three processing temperatures through die-casting. Also, the surface finish of LM20 alloy was found at different three processing temperatures. From the results and discussion, the following conclusions were described.

The grain size of the LM20 alloy was increased with increase in the processing temperatures due to its recrystallization takes place during casting. Therefore, the hardness and tensile strength of LM20 alloy was decreased.

However, the wear rate of the LM20 alloy was found to be increases at various temperatures but, moderate changes were observed with different time durations. Surface roughness of the LM20 alloy was observed to be low at room temperature among three processing temperatures.

Overall, the microstructure of the LM20 alloy was varying at high processing temperatures and the mechanical properties were observed to be decreases with increase in temperature range. Nevertheless, in the present scenario, companies are looking for stabilized, enhanced property products even at elevated temperatures. Hence, to make stabilization of microstructures and for improvement in the mechanical properties need to add some grain refineries which is sustainable at high temperatures.

\section{Acknowledgment}

I would like to thank Mr. Srikanth, Mr. Sachin Kumar, Mr. Pruthvi Raj, Mr. Rakesh Kumar, for their cooperation. Also, I very much gratitude to have continuous support from Dr Mallikarjuna Reddy, Associate Professor, VIT Vellore, Chennai, India.

\section{References}

[1] J. R. Davis, "Aluminum and Aluminum Alloys," Ohio, ASM international, 1993, pp. 627.

[2] V. A. Hosseini, S. G. Shabestari, and R. Gholizadeh, "Study on the effect of cooling rate on the solidification parameters, microstructure, and mechanical properties of LM13 alloy using cooling curve thermal analysis technique," Materials and Design, Vol. 50, 2013, pp. 7-14.

[3] A. Maleki, A. Shafyei, and B. Niroumand, "Effects of squeeze casting parameters on the microstructure of LM13 alloy," Journal of materials processing technology, Vol. 209, 2009, pp. 3790-3797.

[4] S. Hegde, and K. Narayan Prabhu, "Modification of eutectic silicon in Al-Si alloys," Journal of materials science, Vol. 43, 2008, pp. 30093027.

[5] M.M. Makhlouf, and H. V. Guthy, "The aluminum-silicon eutectic reaction: mechanisms and crystallography," Journal of light metals, Vol. 1, 2001, pp. 199-218

[6] S. Shankar, Y. W. Riddle, and M. M. Makhlouf, "Nucleation mechanism of the eutectic phases in aluminum-silicon hypoeutectic alloys," Acta Materialia, Vol. 52, 2004, pp. 4447-4460.

[7] M. Patel, and Prasad Krishna, "A review on application of artificial neural networks for injection moulding and casting processes," International Journal of Advances in Engineering Sciences, Vol. 3, 2013, pp. 1-12.

[8] C. H. Fan, Z. H. Chen, W. Q. He, J. H. Chen, and D. Chen, "Effects of the casting temperature on microstructure and mechanical properties of the squeeze-cast $\mathrm{Al}-\mathrm{Zn}-\mathrm{Mg}-\mathrm{Cu}$ alloy." Journal of alloys and compounds, Vol. 504, 2010, pp. L42-L45.

[9] A. Maleki, B. Niroumand, and A. Shafyei, "Effects of squeeze casting parameters on density, macrostructure and hardness of LM13 alloy," Materials Science and Engineering: A, Vol. 428, 2006, pp. $135-140$.

[10] R. J. Wang, J. Zeng, and D. Zhou, "Determination of temperature difference in squeeze casting hot work tool steel," International journal of material forming, Vol. 5, 2013, pp. 317-324.

[11] A. Kumar, C. Veeresh Nayak, M. A. Herbert, and S. S. Rao, "Microstructure and hardness of friction stir welded aluminium- 
copper matrix-based composite reinforced with 10 wt- $\%$ SiCp," Materials Research Innovations, Vol. 18, 2014, pp. S6-84.

[12] P. Molnar, and A. Jager, "Multi-temperature equal channel angular pressing of Mg-3 wt\%Al-1 wt\%Zn alloy," Philosophical Magazine, 2013, pp. 1-15.

[13] M. G. C. Patel, M. Robins, P. Krishna, and M. B. Parappagoudar, "Investigation of squeeze cast process parameters effects on secondary dendrite arm spacing using statistical regression and artificial neural network models," Procedia Technology, Vol. 14, 2014, pp. 149-156.

[14] M. G. C. Patel, P. Krishna, and M. B. Parappagoudar, "Prediction of secondary dendrite arm spacing in squeeze casting using fuzzy logic based approaches," Archives of Foundry Engineering, Vol. 15, 2015, pp. 51-68.

[15] V. J. Rao, C. Joshi, A. Bapat, and M. Kosamba, “ Modification of die cast hypoetectic Al-Si alloy with different sources of Nickel and its effect on mechanical properties," International Journal of Science, Environment, Vol. 3, 2014, pp. 492-496.

[16] B. K. Kim, S. Y. Lee, and M. Xu. "Polyurethanes having shape memory effects," Polymer, Vol. 37, 1996, pp. 5781-5793.

[17] A. Muralidhar, S. Narendranath, and S. H. Nayaka, "Effect of equal channel angular pressing on AZ31 wrought magnesium alloys," Journal of Magnesium and Alloys, Vol. 1, 2013, pp. 336-340.

[18] A. Azushima, R. Kopp, A. Korhonen, D. Y. Yang, F, Micari, G. D. Lahoti,and A. Yanagida, "Severe plastic deformation (SPD) processes for metals," CIRP Annals - Manufacturing Technology, Vol. 57, 2008, pp. 716-735.

[19] M. Avvari, and S. Narendranath, "Influence of Route-R on wrought magnesium AZ61 alloy mechanical properties through equal channel angular pressing," Journal of Magnesium and Alloys, 2014, pp. 4-9.

[20] R. N. Rao, S. Das, D. P. Mondali, G. Dixit, S. L. Tulasi Devi, "Dry sliding wear maps for AA7010 (Al- $\mathrm{Zn}-\mathrm{Mg}-\mathrm{Cu}$ ) aluminium matrix composite," Tribology International, Vol. 60, 2013, pp. 77-82.
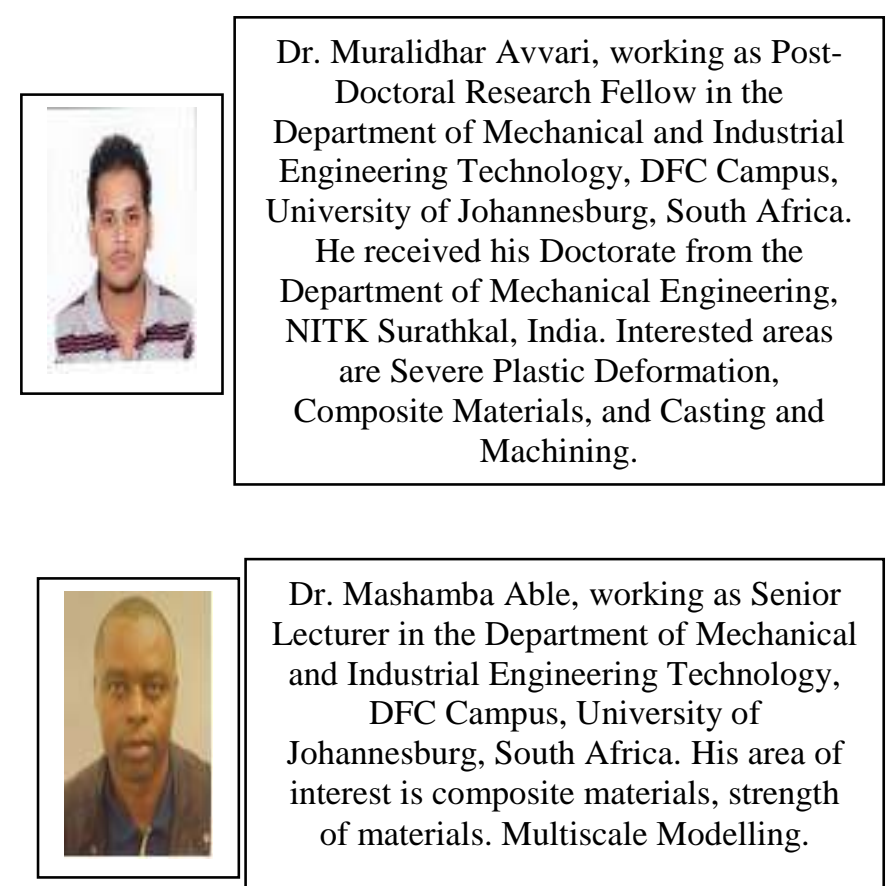

Dr. Mashamba Able, working as Senior Lecturer in the Department of Mechanical and Industrial Engineering Technology, DFC Campus, University of Johannesburg, South Africa. His area of interest is composite materials, strength of materials. Multiscale Modelling. 